\title{
Endothelial vascular smooth muscle cell
} coculture assay for high throughput screening assays to identify antiangiogenic and other therapeutic molecules

REVIEW

\section{George A Truskey}

Department of Biomedical Engineering, Duke University, Durham, NC, USA
Correspondence: George A Truskey I36 Hudson Hall, CB 9028I, Department of Biomedical Engineering, Duke University, Durham, NC 27708-028I, USA

$\mathrm{Tel}+19196605147$

$\mathrm{Fax}+19196844488$

Email gtruskey@duke.edu

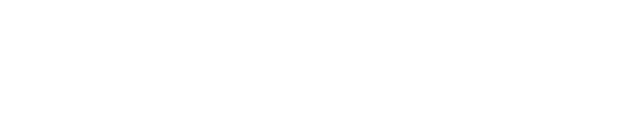

\begin{abstract}
Drug development for many diseases would be aided greatly by accurate in vitro model systems that replicate key elements of in vivo physiology. The recent development of coculture systems of endothelial cells and vascular smooth muscle cells can be extended to high-throughput systems for the identification of compounds for angiogenesis, vascular repair, and hypertension. In this review, the various coculture systems are reviewed, and biologic interactions between endothelial cells and vascular smooth muscle cells are discussed. Key considerations in the design of high-throughput systems are presented, and selected examples are discussed.
\end{abstract}

Keywords: endothelium, vascular smooth muscle cells, angiogenesis, microfluidics

\section{Introduction}

In spite of significant progress, clinical complications of cardiovascular disease, such as heart attack and stroke, remain the leading causes of death in many developed and developing countries. While deaths due to cardiovascular events, such as vessel occlusion, have declined, the incidence of heart failure and diabetes is increasing. New therapeutic approaches are needed to treat cardiovascular diseases, including atherosclerosis, heart failures, diabetes, and hypertension.

A wide range of drugs is available to treat both key risk factors and pathologic manifestations of cardiovascular disease. These include thrombolytic drugs, such as type 1 tissue plasminogen activator to rapidly dissolve clots; antiplatelet and anticoagulants to reduce the likelihood of clot formation; a variety of channel blockers to regulate muscle contraction and arrhythmias; drugs to regulate plasma cholesterol (eg, statins) or classes of lipoproteins; vasodilators, such as nitroglycerin; antihypertensive drugs, ranging from diuretics to specific pathway inhibitors; antiproliferative drugs; and drugs that promote or inhibit angiogenesis. Many patients have several underlying risk factors for cardiovascular disease and take multiple medications.

Drugs that treat cardiovascular disease act on platelets, neutrophils, and cardiac muscle, as well as endothelium cells (ECs) and smooth muscle cells (SMCs). Drugs acting on the endothelium regulate thrombosis, angiogenesis, and the expression of molecules that mediate inflammation. Other drugs mimic vasodilators released by the endothelium. Treatments directed at SMCs affect contraction and growth.

In spite of the range of drugs available, drug treatments for heart failure, diabetes, hypertension, cardiac conduction abnormalities, and stroke are far from ideal. Currently, 
drug discovery involves in vitro biochemical tests and/or population studies to identify targets, followed by screening of compounds to identify promising leads. ${ }^{1}$ For the most part, limited in vitro characterization of potential leads occur before animal studies. The lead studies involve biochemical and cell culture studies with cell lines. If a promising candidate is identified, then human clinical trials would commence. Safety studies come first, followed by studies of efficacy and side effects (see www.nlm.nih.gov/services/ctphases.html). The overall process is lengthy, with drug development taking 10-15 years before approval, and the overall success rate is low. ${ }^{2}$ The cost of developing new drugs has risen dramatically over the past 10 years, with compound rates of growth exceeding $7 \%{ }^{3}$

While the process of drug discovery has changed due to scientific advances, the rate at which companies produce new drugs each year remains relatively constant. ${ }^{4}$ The current approach of target and lead identification has been criticized as being too focused, resulting in drug candidates that have limited efficacy or unexpected side effects. ${ }^{1}$ Target identification needs to be performed under conditions such that physiologic and pathologic roles can be assessed. The lead identification process must be robust enough to assess the effect of changes to the target activity induced by the drug candidate under a range of physiologic conditions.

Recent advances in cell culture technology and microfluidics have enabled the development of cell culture systems that can more accurately represent in vivo conditions. These technologies can be integrated into high-throughput systems to complement existing screening approaches. In this article, we discuss the potential of high-throughput cocultures of ECs and SMCs to aid in the identification of promising drug candidates for vascular disease, thereby complementing the existing approaches to identify lead candidates. Coculture provides a better model of the in vivo environment under normal and disease conditions, allowing complex conditions to be approximated.

\section{Function of vascular endothelium}

Blood vessels consist of three layers, ie, the intima, media, and adventitia. The intima is the layer closest to blood, and the endothelium forms a continuous lining in contact with blood. The endothelium rests on a basement membrane rich in collagen IV and laminin, which interacts with collagens I and III. The intima is separated from the media by layers of elastin. The elastic layer varies from a loose structure in veins to a series of well-defined lamella in the larger elastic arteries. The media contains alternating bands of SMCs and extra- cellular matrix consisting of collagen I and proteoglycans. Collagen I is the most abundant protein in blood vessels and, together with elastin, gives the vessel its passive mechanical behavior. The adventitia is a loose connective tissue containing fibroblasts. While the intima and inner media can receive sufficient nutrients from blood, thicker arteries and veins have a capillary and lymphatic supply in the outer media and adventitia.

ECs and SMCs are the major cellular components of arteries and veins. ECs form a continuous lining at the interface between blood and tissue, and are present in all blood vessels. ECs serve as a nonthrombogenic surface and a structural barrier between the circulation and the surrounding tissue. ECs regulate the entry of leukocytes into tissues.

ECs inhibit platelet deposition and aggregation, as well as clot formation due to the secretion of molecules, including tissue factor pathway inhibitor, tissue plasminogen activator (tPA), prostacyclin, and nitric oxide (NO) and expression of anticoagulants on the cell membrane, such as heparin sulfate, ADPase, and thrombomodulin. ${ }^{5} \mathrm{NO}$ also blocks leukocyte adhesion. During vessel injury, ECs promote thrombosis by activation of tissue factor and secretion of plasminogen activator inhibitor-1 (PAI-1) and von Willebrand factor.

Vascular endothelium responds specifically to arterial levels of fluid shear stress, but less so to pressure or cyclic stretch. ${ }^{6}$ Steady or pulsatile laminar shear stresses cause the endothelium to align in the direction of flow, release vasodilators, reduce their growth rate, increase their elastic modulus, and increase expression of genes that promote an anti-inflammatory state. In contrast, low and oscillating shear stresses promote the release of vasoconstrictors and antithrombotic factors and the expression of proinflammatory and oxidative stress genes. ${ }^{6,7}$

ECs are activated by bacterial endotoxin, cytokines, thrombin, low oxygen concentrations, and spatial gradients in shear stress or oscillatory shear stress. ${ }^{8}$ Activated ECs cease to produce antithrombotic and anticoagulant factors, such as tPA and thrombomodulin, and produce tissue factor, von Willebrand factor, PAI-1, thrombospondin, collagen, platelet-activating factor, chemoattractant molecules, and cell adhesion molecules. ${ }^{9}$ Once activated, leukocytes in the flowing blood adhere to and transmigrate across the endothelium to remove the toxins or cells.

The capillary endothelium forms a continuous monolayer in which the borders of each cell are in contact. Capillaries consist of a single layer of ECs with occasional pericytes present in the basement membrane. ${ }^{10}$ The short distances between the capillary endothelium and the tissue enable efficient solute and solvent exchange between the blood and tissues. ECs are linked 
at their junctions by a range of proteins that form adhesion plaques and tight junctions. ${ }^{11}$ Permeability is regulated by the frequency of tight junctions between ECs and the presence of openings within the endothelium, termed fenestra.

The endothelium adapts to the needs of a specific tissue or organ. Thus, tissues and organs involved in movement of cells and proteins (eg, liver, spleen) have endothelium with few tight junctions and numerous fenestrae that provide the cells with high permeability, whereas organs that restrict transport have endothelium with high levels of tight junction proteins and low permeability (eg, brain). Likewise, spatial variation in pro- and anticoagulant molecules influence how different vascular beds respond to flow stasis or injury. ${ }^{5}$ Inducible changes in permeability due to release of molecules, such as histamine and leukocyte trafficking, generally occurs in postcapillary venules.

New capillaries form during development, as well as in wound healing, during ovulation, or as part of the development of the placenta. ${ }^{12}$ Certain pathologies induce angiogenesis, such as cancer, atherosclerosis, and diabetic retinopathy. ${ }^{13}$ The process of new vessel formation is stimulated by local hypoxia or a gradient in angiogenic molecules, such as vascular endothelial growth factor (VEGF), and involves numerous molecular and cellular interactions. Sprouting of ECs from existing vessels is a complex process that involves binding of VEGF to one of its receptors, and cell migration through the extracellular matrix and interaction with laminin and collagen IV. Maturation and stabilization of the blood vessel requires fibroblast growth factor, pericytes, and collagen $\mathrm{IV}^{12}$

Angiogenesis can have positive and negative effects upon the progression of cardiovascular disease. New capillaries that provide collateral circulation in a region of blood vessel obstruction provide key nutrients to the surrounding tissue and limit the impact of the obstruction. However, new vessel formation in the interior of plaques may facilitate the growth of the plaque such that it can then compromise blood flow and nutrient delivery.

\section{Function of vascular smooth muscle cells}

SMCs are present in the media and control the tone of the vessel wall. SMCs are normally in a quiescent state and express high levels of contractile proteins (SMC $\alpha$-actin and $\gamma$-actin, calponin, myosin, and myosin heavy chain kinases). ${ }^{14}$ During development, SMCs secrete the major extracellular proteins that give the vessel wall its unique mechanical properties. ${ }^{15}$ In adult blood vessels, the SMCs have low levels of protein synthesis. ${ }^{15}$ The SMCs possess isoforms of the contractile protein found in striated cardiac and skeletal muscle, but vascular SMCs are less metabolically active than in striated muscle.

SMCs can exist in a proliferative, synthetic, or contractile phenotype in vitro and in vitro. The normal state of SMCs in the arteries of mature humans and animals is a contractile phenotype with little protein synthesis or cell replication, which can shift dramatically after injury or culture in vitro.

Vascular SMCs are sensitive to cyclic stretch arising from the periodic distension of the vessel wall during the cardiac cycle. Periodic stretch increases the production of growth factors, extracellular matrix proteins, and contractile proteins. ${ }^{16}$ Pressure differences across the arterial wall produce a fluid flow that generates shear stresses on vascular SMCs. Shear stresses have been estimated to be in the $0.1-1 \mathrm{dyne} / \mathrm{cm}^{2}$ range, ${ }^{17}$ and these shear stresses affect the contractile state of SMCs, NO release, cell migration, and the expression of matrix metalloproteinases. ${ }^{18,19}$

SMCs regulate the diameter of medium-sized arteries and arterioles in response to changes in blood pressure, a process known as myogenic autoregulation. At low blood pressures, the vessel responds passively and the SMCs are near their resting length. When the blood pressure increases above normal levels, the SMCs are stretched and contract. This contraction maintains the vessel diameter within narrow limits as the pressure varies. The myogenic response is modulated by the local fluid shear and the metabolic demand of tissues downstream of the arterioles. ${ }^{20}$

In atherosclerosis, diabetes, and hypertension, myogenic autoregulation and NO release are impaired, and a process of adaptive remodeling occurs to maintain the stress and wall shear stress on the vessel wall constant in response to changes in flow and/or pressure. Such requirements result in corresponding changes to the vessel wall diameter and thickness. ${ }^{21}$

Injury to the vessel wall exposes blood to the extracellular matrix and SMCs. The SMCs express tissue factor that promotes platelet attachment and thrombosis. Platelets release growth factors that stimulate SMC migration, growth, and extracellular matrix synthesis. Extensive SMC proliferation can narrow or obstruct the vessel lumen, thereby compromising flow.

\section{Interactions between vascular endothelium and smooth muscle cells}

ECs and SMCs interact to maintain the normal function of the vessel wall. While SMCs contract and relax to maintain vessel diameter, the endothelium releases vasodilators and vasoconstrictors to modulate the blood vessel diameter in 
response to changes in blood flow rate or wall shear stress ${ }^{22}$ stimulation by nerves or peptides and hormones present in the blood. Key mediators of vessel dilation produced by the endothelium are prostacyclin and NO, and endothelialderived hyperpolarizing factor (EDHF); NO reacts with soluble guanylate cyclase SMC to produce cyclic guanine monophosphate (cGMP) which, in turn, activates myosin light chain phosphatase that then removes phosphates from myosin and causes relaxation. In contrast, vasoconstrictors, such as endothelin and angiotensin II, cause SMCs to contract. Many of these molecules diffuse freely between the two cell types. NO is highly reactive, and its concentration may be reduced by reactive oxygen species. Thus, short diffusion distances between the endothelium and SMCs are needed for NO to exert its effects on SMCs.

In medium-sized arteries lacking an internal elastic lamina, ECs and SMCs are in close proximity, and occasional gap junctions arise between the two cell types. ECs also release EDHF, which appears to involve $\mathrm{K}^{+}$ion channels that may be activated in gap junctions or by free diffusion of $\mathrm{K}^{+}$or other small molecular weight molecules, such as $\mathrm{H}_{2} \mathrm{O}_{2} \cdot{ }^{23}$

Transforming growth factor beta $\left(\mathrm{TGF}-\beta_{1}\right)$ is a potent inhibitor of proliferation ${ }^{24}$ in many cell types and promotes SMC differentiation. ${ }^{25}$ In vitro, SMCs and ECs cultured alone each produce TGF- $\beta_{1}$ in an inactive form ${ }^{26}$ which is then activated by plasmin produced by urokinase on the EC surface. ${ }^{27}$ TGF- $\beta_{1}$ stimulates extracellular matrix synthesis by SMCs and is expressed in vivo after wounding. ${ }^{28}$ TGF- $\beta_{1}$ is a potent inhibitor of proliferation ${ }^{24}$ and activation by cytokines, and is an inducer of apoptosis ${ }^{29}$ in many cells, including ECs. In direct EC-SMC coculture, higher mRNA levels of TGF- $\beta_{1}$ were found in human SMCs, but TGF- $\beta_{1}$ levels in ECs did not change. ${ }^{30} \mathrm{SMC}$-conditioned medium produced a decrease in TGF- $\beta_{1}$ mRNA in ECs. TGF- $\beta_{1}$ stimulates ET- 1 release by SMCs which could induce SMC contraction. ${ }^{31}$ While addition of exogenous TGF- $\beta_{1}$ induces differentiation of SMCs in two-dimensional culture, it had little effect on SMC differentiation when cells were embedded in three-dimensional collagen gels, ${ }^{32}$ possibly due to binding of TGF- $\beta_{1}$ to collagen or other extracellular matrix proteins. ${ }^{33}$

\section{EC-SMC coculture models}

Due to the interactions that occur between ECs and SMCs, coculture of ECs and SMCs are used to model the normal ${ }^{34}$ and atherosclerotic vessel wall ${ }^{35,36}$ and to simulate angiogenesis. ${ }^{37}$ There are four basic coculture models in use (Figure 1), ie, culture of SMCs and ECs on opposite sides of membranes, ${ }^{38-41}$ culture of ECs on collagen gels or other polymers containing SMCs, ${ }^{42,43}$ microcarrier/spheroid-bound ECs or SMCs,,${ }^{44,45}$ and culture of ECs directly on SMCs ${ }^{46,47}$ or side-by-side. ${ }^{48,49}$ The use of conditioned media ${ }^{40,50}$ is a less direct, but sometimes useful, method of assessing EC-SMC interactions.

A

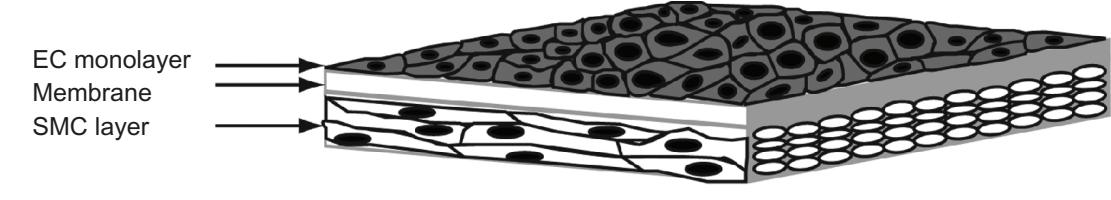

B

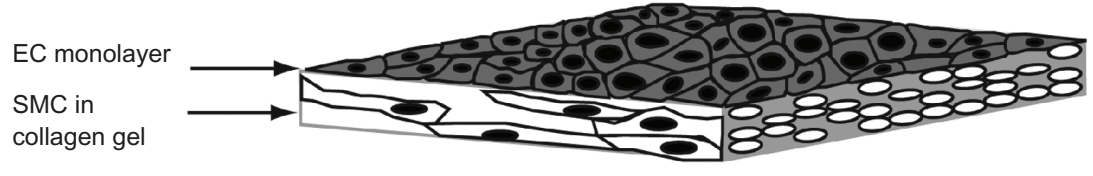

C

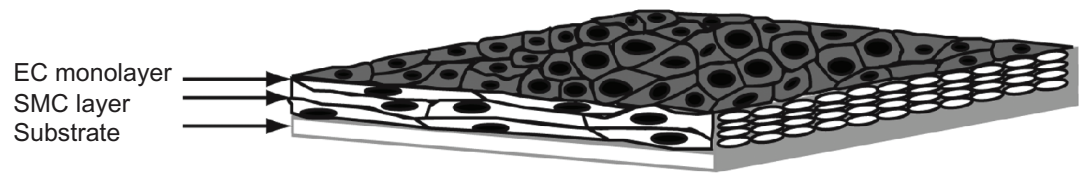

D

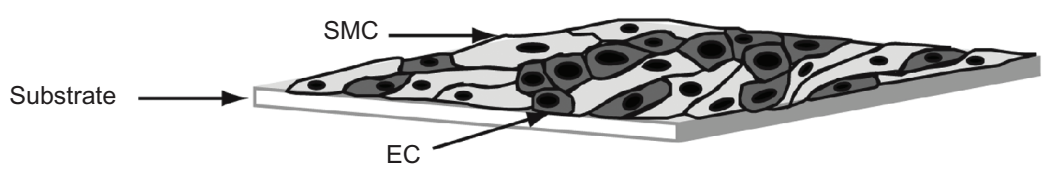

Figure I Schematic of various types of endothelial cell and smooth muscle cell coculture arrangements. A) Culture of endothelial cells and smooth muscle cells on the opposite sides of a porous membrane to facilitate cell separation. B) Culture of endothelial cells on the surface of a gel containing embedded smooth muscle cells. The gel may consist of collagen, fibrin or a synthetic hydrogel. C) Culture of endothelial cells directly above smooth muscle cells to replicate the geometry in arteries and veins. The cells secrete extracellular matrix to produce a basement membrane separating the cells. D) Mixed culture of endothelial cells with smooth muscle cells. This arrangement can rapidly produce capillary-like structures without the addition of growth factors or angiogenesis-promoting molecules, such as vascular endothelial growth factor. Abbreviations: EC, endothelial cells; SMC, smooth muscle cells. 
Because of the relative difference in growth rates of ECs and SMCs and the need to separate the two cell types easily, most coculture techniques involve the separate, but close, culture of the two cell types. Growing the two cell types on opposite sides of cell membranes is an easy way to permit separation of the cells and limit overgrowth, while bringing ECs and SMCs within 10-50 $\mu \mathrm{m}$ of each other. The Transwell cell culture system is well suited for such studies. While the two cell types may form connections through the narrow pores, ${ }^{51}$ the porous membrane limits the interactions between the ECs and SMCs, increasing the diffusion distance ${ }^{52}$ and reducing the frequency of myoendothelial gap junction formation and EC interaction with the extracellular matrix produced by SMCs. The porous membrane also introduces a synthetic and stiffer surface between ECs and SMCs than occurs in vivo, and cell function appears to be very sensitive to the stiffness of the surface on which cells are grown. ${ }^{53}$

Coculture of ECs and SMCs on opposite sides of a thin membrane stimulated SMC proliferation ${ }^{40}$ and upregulated VEGF, platelet-derived growth factor (PDGF)-AA, PDGF-BB, and TGF- $\beta_{1}$ gene expression, and downregulated fibroblast growth factor gene expression. ${ }^{54}$ ECs cultured with SMCs also changed ECs from the normal polygonal morphology in vitro to an elongated shape, ${ }^{42}$ increased EC gene expressions of transcription factor, ${ }^{50} \mathrm{VEGF},{ }^{54}$ adhesion molecules, ${ }^{38}$ growth-related oncogene-, and monocyte chemoattractant protein- $1 .{ }^{35}$ Coculture of ECs with 10T1/2 cells, a smooth muscle-like cell line, produced increased localization of tight junction proteins to the junctions and increased permeability in a manner akin to the effect of cAMP, ${ }^{55}$ suggesting that SMCs play a critical role in regulating EC permeability. ${ }^{38}$

When exposed to a physiologic shear stress of $15 \mathrm{dyne} / \mathrm{cm}^{2}$ for 72 hours, $G_{\mathrm{ia3}}$ protein expression by EC cocultured with SMC on opposite sides of a semipermeable capillary tube was specifically and significantly enhanced compared with cocultured ECs exposed to 0.5 dyne $/ \mathrm{cm}^{2} .{ }^{56}$ This change in $G$ protein was independent of EC NO synthase (NOS III) or cyclo-oxygenase activity. In contrast, cocultured SMC exposed to 15 dyne $\mathrm{cm}^{-2}$ exhibited smaller levels of $\mathrm{G}_{\text {ial-2 }}$ than SMC exposed to low flow. This was independent of the activity of NOS III but was reduced when cyclo-oxygenase activity was inhibited. Effects on SMC depend upon the presence of EC, because SMC exposed to flow alone did not exhibit any changes in $\mathrm{G}$ proteins.

When the two cell types are cultured together without an intervening membrane, they can be separated after trypsin treatment using magnetic beads coated with an antibody that binds to $\mathrm{CD} 31$. This leads to EC populations that are $98.7 \pm 0.7 \%$ (mean \pm standard deviation) pure..$^{57}$ Likewise, almost all of the ECs are separated from SMCs, and the SMC population is also about $98 \%$ pure. A confluent layer of ECs can be maintained on a layer of quiescent SMCs for as long as 30 days.

Direct-contact coculture replicates the growth state and architecture and reduces diffusion distances. In close contact, the extracellular matrix protein synthesis changes. While ECs can migrate into collagen gels and form networks in vitro, these structures are unstable. In contrast, when ECs and SMCs are mixed together, SMCs inhibit EC proliferation, and ECs form capillaries and synthesize collagen IV. ${ }^{37}$ These structures are stable for several weeks. Capillary formation depended upon release of VEGF from SMCs. Mesenchymal stem cells can replicate the effect induced by SMCs, but replacing the SMCs with fibroblasts does not lead to capillary formation. ${ }^{34}$

While ECs synthesize basement membrane proteins, such as collagen II and IV and laminin, when ECs are grown directly above SMCs, a well developed intima has not been produced yet. Alternatively, the in vitro geometry can be mimicked by growing the SMCs in a collagen gel or polymer, such as poly-L-lactic acid. This approach is widely used to develop tissue-engineered blood vessels. ${ }^{58,59}$ In three-dimensional matrices in vitro, cyclic stretch leads to increased stiffness of the matrix ${ }^{58,60}$ resulting from extracellular matrix synthesis and reorganization. ${ }^{16}$ The contractile phenotype can be enhanced by stretch and by incorporating fibronectin binding sequences in the matrix backbone ${ }^{61}$ Only a few studies have examined the interactions between ECs and SMCs in this configuration. ${ }^{62,63}$

The manner in which coculture is performed can significantly affect results. For example, TGF- $\beta_{1}$ release is greater when ECs and SMCs are cultured together in a single layer than on opposite sides of a membrane. When cultured together, the contact and diffusion distances are minimized. Further, direct culture of ECs on SMCs led to a reduction in the responsiveness of ECs to tumor necrosis factor alpha, whereas the effect was greatly reduced when the cells were grown on the opposite of a porous membrane. ${ }^{64}$

Proliferating SMCs in culture model the phenotype of SMCs after vessel wall injury and induce an inflammatory state within ECs by increasing EC NF- $\kappa B$ p 65 and p50 mRNA expression, NF-אB-DNA binding activity, ${ }^{36}$ EC ICAM-1, VCAM-1, and E-selectin mRNA expression, ${ }^{36,38}$ and leukocyte adhesion to ECs with ${ }^{65}$ or without the presence of tumor necrosis factor- $\alpha .{ }^{36}$ In contrast, quiescent SMCs did not affect adhesion molecule expression and NF- $\kappa B$ nuclear translocation 
in the absence of cytokines and reduced the EC inflammatory response to tumor necrosis factor- $\alpha \cdot{ }^{64} \mathrm{~A}$ limitation of this study is that the SMCs are likely not contractile, even though the ECs do promote differentiation of SMCs. During atherosclerosis, SMCs may aid in the activation of ECs, while SMCs within a healthy vessel may limit EC activation.

While each method of coculture has distinct advantages, methods of direct coculture most closely mimic the structure of the vessel wall and can produce stable capillaries. Further, direct contact coculture assays use fewer cells than the tissue-engineered blood vessels and, as discussed below, can be readily adapted for high-throughput applications. The two major limitations of this approach are that longer culture times may be needed to produce an intima that resembles the in vivo structure, and the combined effect of flow and stretch has not been studied. While tissue-engineered blood vessels mimic the in vivo geometry and can be incorporated into flow systems that permit variation of flow and pressure that model physiologic conditions, these vessels may not be suitable for high-throughput applications. However, tissueengineered blood vessels can be utilized after a small number of lead candidates have been developed.

\section{High-throughput screening assays Overview}

High-throughput systems enable screening of a large number of compounds. Ideally, these systems are automated to perform rapid screening with minimal user error. Outputs should be quantifiable and related to the function of the cell. Because of the cost of reagents and cell culture systems, small volumes are preferable. Small volumes and characteristic lengths reduce the time for diffusion and reaction. ${ }^{66}$ Because small numbers of cells exhibit stochastic variations in gene and protein expression, the system must be large enough that a sufficient number of cells are present to ensure representative behavior of the population and to enable application of the polymerase chain reaction or gene microarray analysis. A further practical consideration is the ability of the cell culture system to interface with other diagnostic technology in the laboratory.

While there are several options for cell culture for high-throughput screening, no approach is ideal. ${ }^{67}$ The drug industry favors the use of cell lines because they can be grown easily and are relatively homogeneous. However, these cell lines may differ from the cells in their native environment and may lack certain metabolic responses. Thus, side effects may be overlooked. Primary cells in culture often retain many aspects of the differentiated cells in vivo, but primary cells cannot be obtained for all cell types. Stem cells can, in principle, differentiate into any cell type, but the cells are difficult to grow in culture and may not differentiate fully ${ }^{68}$ Induced pluripotent stem cells represent a promising option, ${ }^{68}$ although a proof of principle for drug discovery is needed.

Primary human vascular ECs and SMCs from arteries or veins can be readily obtained after a surgical procedure, and microvascular human ECs can be obtained from adipose tissue. However, microvascular cell cultures derived from adipose tissue are often contaminated with macrophages and fibroblasts which can lead to intimal hyperplasia and inflammation upon reimplantation. ${ }^{69}$ Therefore, extra precautions are needed to ensure a pure population of ECs when using adipose tissue.

Late outgrowth endothelial progenitor cells ${ }^{70}$ can be isolated from human blood, do not exhibit cell surface markers for monocytes or other white blood cells, grow well, and exhibit many properties of vascular endothelium. These cells can be isolated from individuals with cardiovascular disease and respond to flow in the same manner as vascular endothelium. ${ }^{71}$ While there are reports that vascular SMCs can be isolated from blood, ${ }^{72}$ the numbers may be limited. Mesenchymal stem cells can be induced to differentiate into SMCs when cultured with vascular endothelium, so these cells may be a source of SMCs. ${ }^{73}$

Readouts from cell culture systems involve a combination of genomic and proteomic information, as well as microscopic observation. This could involve measurements of cell sprouting or network formation during angiogenesis, or monitoring of protein expression or signaling using fluorescent probes.

Ideally, the culture system should mimic key features of the in vivo environment to ensure that the responses are close to those in vivo. This requires three-dimensional high cell density cultures with multiple cell types responding to physical forces. Some very elegant systems have been developed to replicate organ scale physiology in a small environment. ${ }^{74}$ Cost and complexity may make such replication prohibitive for early-stage testing, but such systems may be useful after lead drug candidates have been identified.

The ease with which EC-SMC coculture systems can be developed makes them promising candidates for highthroughput applications. Microplates, cells cultured onto glass slides with micropatterned arrays, ${ }^{75}$ and microfluidic flow systems meet many of the key criteria for cell culture and high-throughput screening. ${ }^{76}$ Microplate systems are widely used for many diagnostic applications and interface with a number of spectrometers, microscopes, and gene array devices. Transwell systems for coculture of ECs and SMCs on opposite sides of membranes utilize multiwall plates that 
range from 6 wells to 96 wells so they can be adapted to high-throughput screening.

\section{Microplate systems}

Several high-throughput microplate systems have been developed to analyze drug candidates that affect angiogenesis. The most commonly used methods are adapted from the classical endothelial gel migration assay. In the high-throughput version of these assays, ECs are placed either above a thin gel of collagen I or $\mathrm{II}^{77}$ or Matrigel, a tumor-derived basement membrane, ${ }^{78}$ or in a well placed within the center of gel.$^{77}$ The systems can be prepared in multiwall plates to observe EC sprouting or cord formation or to collect samples for genomic analysis. The dynamics of sprouting and network formation can be quantified using commercially available software or custom programs written with the NIH ImageJ software that is available for free (see http://rsbweb.nih.gov/ij/). While collagen gels are well defined and specific angiogenic promoters or inhibitors can be added, the collagen gels do not form capillary-like structures and are unstable. Matrigel permits the formation of capillary-like structures in about 10 hours, but the structures disintegrate after 24 hours. Further, Matrigel is poorly defined and can promote sprouting by fibroblasts, suggesting that it is not specific to endothelium.

An important consideration in developing a quantitative assay is the ability to manipulate the concentration of the compounds inducing angiogenesis. This is clearly a limitation of the use of Matrigel because neither the gradient nor the amount of VEGF or other growth factors is controlled. In the microplate assays, the collagen gel thickness is often too great to produce stable concentration gradients in a reasonable time. Consequently, VEGF or other growth factors are often mixed into collagen gel to produce a uniform concentration. However, due to diffusion and metabolism, gradients arise which can affect the subsequent cellular response. In spite of these limitations, Matrigel is still commonly used, and reproducible data are obtained.

Coculture systems offer the advantage of producing stable microvessels. Evensen et $\mathrm{al}^{79}$ developed a very useful microplate coculture system to quantify angiogenesis. Human umbilical vein ECs and pulmonary artery vascular SMCs were mixed together and then cultured in 96-well plates. The principal output was network formation, which was measured by expressing either green fluorescent protein or a derivative in the ECs. The tube length was measured over time using image analysis software and found to be stable after three days. As a proof of principle, the assay was sensitive to tyrosine kinase inhibitors of VEGF receptor 2.
The assay correctly predicted the effectiveness of several inhibitors in a double-blind assay. Further, the method can be used to generate dose-response curves.

Although the method of Evensen et al ${ }^{79}$ could potentially be extended to examine promoters of angiogenesis, the assay was principally applied to the identification of angiogenesis inhibitors. A clear benefit of this coculture system over the use of gels is that a stable network was formed without creating a gradient of VEGF. A limitation of the approach is the time required to reach a stable network.

\section{Microfabrication methods}

Microfabrication techniques can be used to create regions of various sizes that either permit or block protein adsorption. Cells will selectively attach and spread in those regions containing proteins. For example, cell attachment is inhibited on a very nonpolar surface or one to which polyethylene glycol or a brush copolymer is attached. Cells will attach to a polylysine surface ${ }^{75}$ or one containing an adsorbed adhesion protein. The size of the cell attachment island can be varied to study the interaction of clusters of cells or individual cell

A

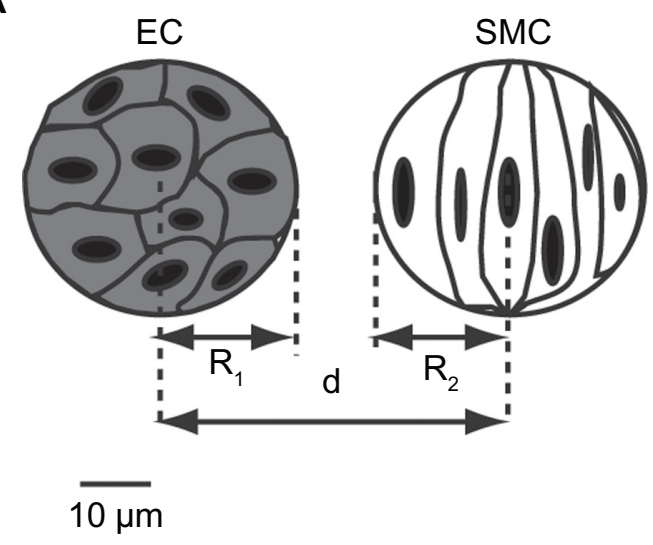

B

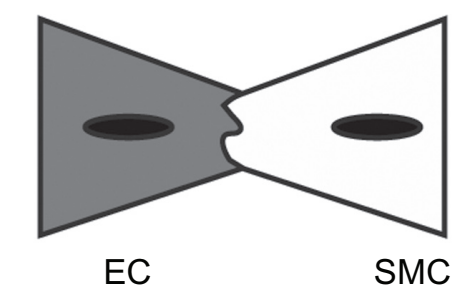

$10 \mu \mathrm{m}$

Figure 2 Examples of micropatterns to arrange endothelial cells and smooth muscle cells. A) Culture of clusters of endothelial cells and smooth muscle cells in islands of radii $R_{1}$ and $R_{2}$, respectively. The islands are separated by a distance $d$. $B$ ) The islands are in direct contact and the length of contact can be varied.

Abbreviations: EC, endothelial cells; SMC, smooth muscle cells. 
pairs (Figure 2). By varying the distance between islands ( $\mathrm{d}$ in Figure $2 \mathrm{~A})$, the island radius ( $\mathrm{R}_{1}$ and $\mathrm{R}_{2}$ in Figure $2 \mathrm{~A}$ ) or the contact distance of adjacent islands, the role of cell-contact and autocrine and paracrine factors can be established. Such microfabricated devices may prove useful in screening for very specific targets related to the initiation of angiogenesis or after cell injury.

Because SMCs are sensitive to mechanical stretch, microfabrication can be used to create an array of cell culture surfaces that can be exposed to different mechanical stimuli. ${ }^{80}$ SMCs are cultured on a deformable substrate overlaying a loading post which, in turn, rests on an actuator. Deformation of the membrane is induced by positive pressure. As expected, strains are nonuniform near edges, but a smaller cavity radius appeared to work better. The strain distribution can be determined computationally and cells are examined only in the region of uniform strain. Strains as high as $16 \%$ can be produced.

\section{Microfluidic systems}

Several microfluidic systems have been developed to study angiogenesis. ${ }^{81}$ These systems provide several important improvements over microplate assays. The volumes are very small. Diffusion distances between cells or between cells and fluid are short and comparable with in vivo dimensions. Many different geometries can be used and experimental variables can be well controlled. Because the flow rates and dimensions are low, Reynolds numbers are much less than one and mixing is minimal. As a result, stable gradients of growth factors can be produced by use of flow systems or relatively large reservoir volumes and visualized using fluorescent labels. ${ }^{82}$ Further, these gradients are on the scale of those occurring in vivo.
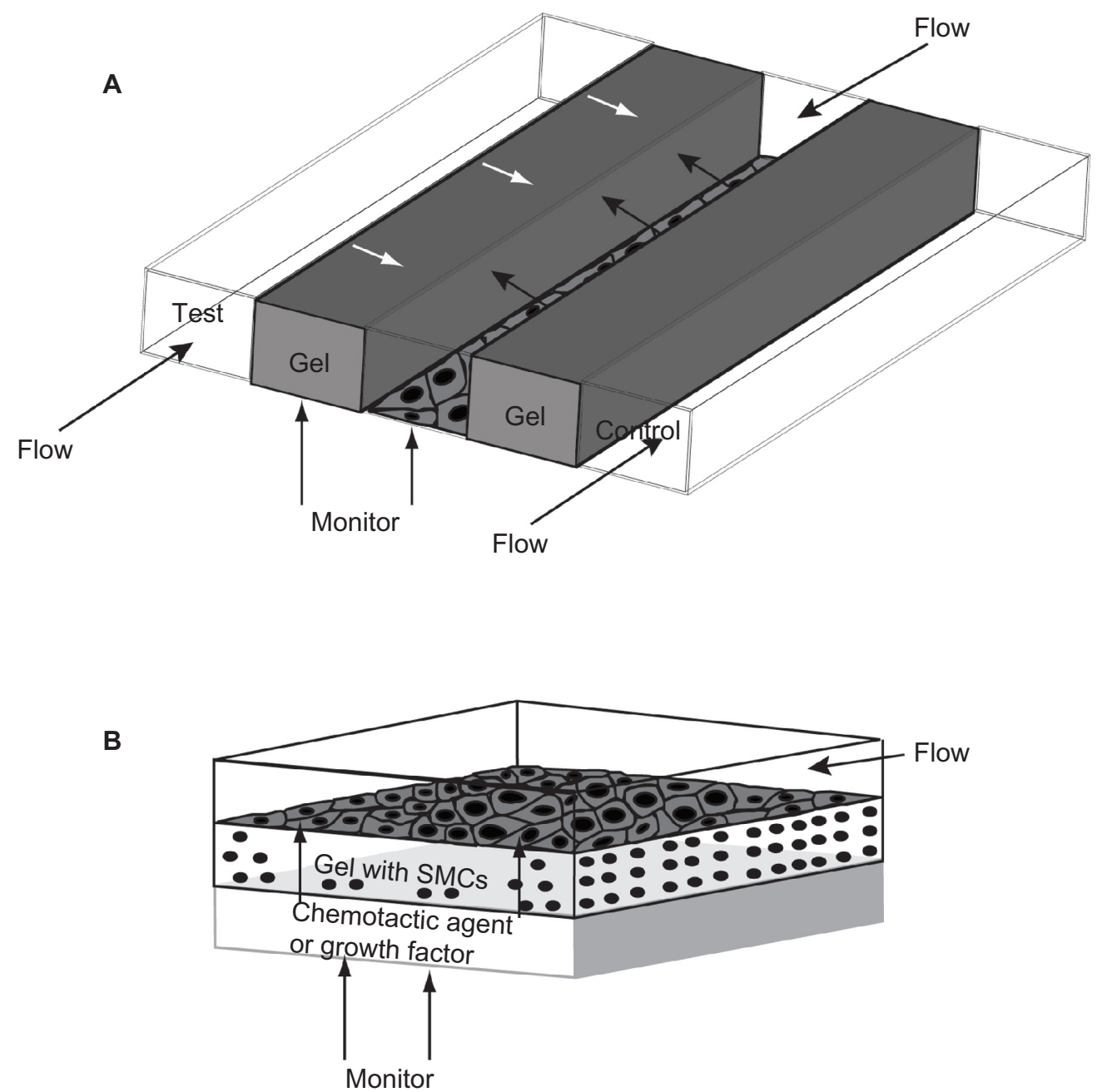

Figure 3 Arrangement of microfluidic channels to study angiogenesis. A) A confluent layer of endothelial cells form in the central channel which is separated from the side channels by walls consisting of a porous gel. The gel can contain smooth muscle cells. A promoter or inhibitor of angiogenesis is introduced on the left hand side and sprout and capillary network formation are monitored. The channel on the right serves as a control. B) Endothelial cells are grown on the surface of a gel containing smooth muscle cells. Both geometries allow the endothelial cells to be exposed to flow and the cells can be monitored by a microscope system.

Abbreviation: SMC, smooth muscle cells. 
Shown in Figure 3 are two of many possible designs of microfluidic channels to evaluate angiogenesis. In Panel A is a design that allows side-by-side testing of an angiogenesis promoter or inhibitor and a control. The gels separating the channels are produced from collagen or a synthetic hydrogel. Posts may be needed to provide structural support for the gel. ${ }^{81}$ ECs are seeded in the central channel and are first allowed to form a confluent layer. Then the test compound is added on the left side to establish a gradient, and sprout formation is monitored with a microscope. A control compound on the right hand side is then used to assess any random migration. This design also permits the investigator to assess the effect of flow on EC sprout formation. For flow studies, the channel height should be less than $10 \%$ of the channel width to ensure that the shear stresses on the cells are uniform. ${ }^{83}$ Several channel units for angiogenesis can be placed in parallel to permit dose-response studies.

To use the microfluidic channels for coculture studies, the SMCs are plated in adjacent channels or placed in the gel before introduction of the ECs. The gel sizing must be calibrated to account for contraction of the gel by the SMCs. With the geometry presented in Figure 3A, chemotactic agents or drugs that promote or inhibit angiogenesis can be used in conjunction with cells immobilized with SMCs.

A three-dimensional structure can be developed to replicate the structure of the vessel wall (Figure 3B). With this geometry, confocal microscopy is needed to study sprouting and network formation, although the assay can be used to assess gene expression resulting from EC-SMC interactions.

In addition to angiogenesis, these assays can be adapted to examine a number of other responses. By quantifying fluorescence intensity and including suitable controls, several parameters can be assessed, including surface expression of adhesion molecules following a stimulus, such as a cytokine or other inflammatory agent, ${ }^{38,84} \mathrm{NO}$ release, redox reactions, ${ }^{85}$ and reporter gene expression.

\section{Conclusion}

EC-SMC coculture systems are sufficiently developed such that they can be utilized for high-throughput screening applications. Several different approaches are available to develop drugs and identify targets for arteries and angiogenesis. Direct contact coculture systems offer several distinct advantages, although these systems still need further development so that a normal intima can be produced and the cells can be exposed to both stretch and fluid flow. Microplate and microfluidic systems can be used to produce high-throughput formats for lead candidate identification.

\section{Acknowledgment}

This work was supported by National Institutes of Health grant HL-88825.

\section{Disclosure}

The author reports no conflicts of interest related to this work.

\section{References}

1. Sams-Dodd. Target-based drug discovery: Is something wrong? Drug Discov Today. 2005;10(2):139-147.

2. DiMasi JA, Feldman L, Seckler A, Wilson A. Trends in risks associated with new drug development: Success rates for investigational drugs. Clin Pharmacol Ther. 2010;87(3):272-277.

3. DiMasi JA, Hansen RW, Grabowski HG. The price of innovation: New estimates of drug development costs. J Health Econ. 2003;22(2): $151-155$.

4. Monus B. Lessons from 60 years of pharmaceutical innovation. Nat Rev Drug Discov. 2009;8(12):959-968.

5. Aird WC. Phenotypic heterogeneity of the endothelium: I. Structure, function, and mechanisms. Circ Res. 2007;100(2): $158-173$.

6. Davies PF. Flow-mediated endothelial mechanotransduction. Physiol Rev. 1995;75(3):519-560.

7. Passerini AG, Polacek DC, Shi C, et al. Coexisting proinflammatory and antioxidative endothelial transcription profiles in a disturbed flow region of the adult porcine aorta. Proc Natl Acad Sci USA. 2004;101(8): 2482-2487.

8. Brown M, Wallace CS, Truskey GA. Vascular and capillary endothelium. In: Akay, M, editor. Wiley Encyclopedia of Biomedical Engineering. John Wiley and Sons; 2006.

9. Cines DB, Pollak ES, Buck CA, et al. Endothelial cells in physiology and in the pathophysiology of vascular disorders. Blood. 1998;91(10): 3527-3561.

10. Armulik A, Abramsson A, Betsholtz C. Endothelial/pericyte interactions. Circ Res. 2005;97(6):512-523.

11. Ogunrinade O, Kameya GT, Truskey GA. Effect of fluid shear stress on the permeability of the arterial endothelium. Ann Biomed Eng. 202;30(4):430-446.

12. Adams RH, Alitalo K. Molecular regulation of angiogenesis and lymphangiogenesis. Nat Rev Mol Cell Biol. 2007;8(6): 464-478.

13. Folkman J. Angiogenesis: An organizing principle for drug discovery? Nat Rev Drug Discov. 2007;6(4):273-286.

14. Owens GK. Regulation of differentiation of vascular smooth muscle cells. Physiol Rev. 1995;75(3):487-517.

15. Owens GK, Kumar MS, Wamhoff BR. Molecular regulation of vascular smooth muscle cell differentiation in development and disease. Physiol Rev. 2004;84(3):767-801.

16. Stegemann JP, Hong H, Nerem RM. Mechanical, biochemical, and extracellular matrix effects on vascular smooth muscle cell phenotype. J Appl Physiol. 2005;98(6):2321-2327.

17. Tada S, Tarbell JM. Interstitial flow through the internal elastic lamina affects shear stress on arterial smooth muscle cells. Am J Physiol Cell Physiol. 2000;278(5):H1589-H1597.

18. Rizzo V. Enhanced interstitial flow as a contributing factor in neointima formation: (Shear) stressing vascular wall cell types other than the endothelium. Am J Physiol Heart Circ Physiol. 2009;297(4): H1196-H1197.

19. Shi ZD, Ji XY, Qazi H, Tarbell JM. Interstitial flow promotes vascular fibroblast, myofibroblast, and smooth muscle cell motility in 3-D collagen I via upregulation of MMP-1. Am J Physiol Cell Physiol. 2009;297: H1225-H1234.

20. Secomb TW. Theoretical models for regulation of blood flow. Microcirculation. 2008;15(8):765-775. 
21. Humphrey JD. Mechanisms of arterial remodeling in hypertension: Coupled roles of wall shear and intramural stress. Hypertension. 2008; 52(2):195-200.

22. Buga G, Gold M, Fukuto J, Ignarro L. Shear-stress induced release of nitric oxide from endothelial cells grown on beads. Hypertension. 1991; 17(2):187-193.

23. Parkington HC, Tare M, Coleman HA. The EDHF story: The plot thickens. Circ Res. 2008;102(10):1148-1150.

24. Sporn MB, Roberts AB, Wakefield LM, de Crombrugghe B. Some recent advances in the chemistry and biology of transforming growth factor-beta. J Cell Biol. 1987;105(3):1039-1045.

25. Goumans M, Liu Z, ten Dijke P. TGF-beta signaling in vascular biology and dysfunction. Cell Res. 2009;19(1):116-127.

26. Sato Y, Rifkin DB. Inhibition of endothelial cell movement by pericytes and smooth muscle cells: Activation of a latent transforming growth factor-beta 1-like molecule by plasmin during coculture. J Cell Biol. 1989;109(1):309-315

27. Gleizes PE, Munger JS, Nunes I, et al. TGF-beta latency: Biological significance and mechanisms of activation. Stem Cells. 1997;15(3): 190-197.

28. Majesky MW, Lindner V, Twardzik DR, Schwartz SM, Reidy MA. Production of transforming growth factor beta 1 during repair of arterial injury. J Clin Invest. 1991;88(3):904-910.

29. Schuster N, Krieglstein K. Mechanisms of TGF-beta-mediated apoptosis. Cell Tissue Res. 2002;307(1):1-14.

30. Sato Y, Okada F, Abe M, et al. The mechanism for the activation of latent TGF-beta during co-culture of endothelial cells and smooth muscle cells: Cell-type specific targeting of latent TGF-beta to smooth muscle cells. J Cell Biol. 1993;123(5):1249-1254.

31. di Luozzo G, Bhargava J, Powell RJ. Vascular smooth muscle cell effect on endothelial cell endothelin-1 production. J Vasc Surg. 2000;31(4): 781-789.

32. Stegemann JP, Nerem RM. Altered response of vascular smooth muscle cells to exogenous biochemical stimulation in two- and threedimensional culture. Exp Cell Res. 2003;283(2):146-155.

33. Schmidt A, Geigenmueller S, Voelker W, Seiler P, Buddecke E. Exogenous nitric oxide causes overexpression of TGF- $b_{1}$ and overproduction of extracellular matrix in human coronary smooth muscle cells. Cardiovasc Res. 2003;58(3):671-678.

34. Wallace CS, Champion JC, Truskey GA. Adhesion and function of human endothelial cells co-cultured on smooth muscle cells. Ann Biomed Eng. 2007;35(3):375-386.

35. Chiu JJ, Chen LJ, Chen CN, Lee PL, Lee CI. A model for studying the effect of shear stress on interactions between vascular endothelial cells and smooth muscle cells. J Biomech. 2004;37(4):531-539.

36. Chiu J-J, Chen L-J, Chang S-F, et al. Shear stress inhibits smooth muscle cell-induced inflammatory gene expression in endothelial cells: Role of NF-kappaB. Arterioscler Thromb Vasc Biol. 2005;25(5): 963-969.

37. Evensen L, Micklem DR, Blois A, et al. Mural cell associated VEGF is required for organotypic vessel formation. PLoS One. 2009;4(6): e5798.

38. Chiu JJ, Chen LJ, Lee PL, et al. Shear stress inhibits adhesion molecule expression in vascular endothelial cells induced by coculture with smooth muscle cells. Blood. 2003;101(7):2667-2674.

39. Rainger GE, Stone P, Morland CM, Nash GB. A novel system for investigating the ability of smooth muscle cells and fibroblasts to regulate adhesion of flowing leukocytes to endothelial cells. J Immunol Methods. 2001;255(1-2):73-82.

40. Fillinger MF, Sampson LN, Cronenwett JL, Powell RJ, Wagner RJ. Coculture of endothelial cells and smooth muscle cells in bilayer and conditioned media models. J Surg Res. 1997;67(2):169-178.

41. Nackman GB, Bech FR, Fillinger MF, Wagner RJ, Cronenwett JL. Endothelial cells modulate smooth muscle cell morphology by inhibition of transforming growth factor-beta 1 activation. Surgery. 1996;120(2):418-425.
42. van Buul-Wortelboer MF, Brinkman HJ, Dingemans KP, de Groot PG, van Aken WG, van Mourik JA. Reconstitution of the vascular wall in vitro. A novel model to study interactions between endothelial and smooth muscle cells. Exp Cell Res. 1986;162(1):151-158.

43. Ziegler T, Alexander RW, Nerem RM. An endothelial cell-smooth muscle cell co-culture model for use in the investigation of flow effects on vascular biology. Ann Biomed Eng. 1995;23(3):216-225.

44. Davies PF, Truskey GA, Warren HB, O'Connor SE, Eisenhaure BH. Metabolic cooperation between vascular endothelial cells and smooth muscle cells in co-culture: Changes in low density lipoprotein metabolism. J Cell Biol. 1985;101(3):871-879.

45. Korff T, Kimmina S, Martiny-Baron G, Augustin HG. Blood vessel maturation in a 3-dimensional spheroidal coculture model: Direct contact with smooth muscle cells regulates endothelial cell quiescence and abrogates VEGF responsiveness. FASEB J. 2001;15(2):447-457.

46. Niwa K, Kado T, Sakai J, Karino T. The effects of a shear flow on the uptake of LDL and acetylated LDL by an EC monoculture and an ECSMC coculture. Ann Biomed Eng. 2004;32(4):537-543.

47. Wada Y, Sugiyama A, Kohro T, et al. In vitro model of atherosclerosis using coculture of arterial wall cells and macrophage. Yonsei Med J. 2000;41(6):740-755.

48. Hirschi KK, Rohovsky SA, D’Amore PA. PDGF, TGF-beta, and heterotypic cell-cell interactions mediate endothelial cell-induced recruitment of $10 \mathrm{~T} 1 / 2$ cells and their differentiation to a smooth muscle fate. $J$ Cell Biol. 1998;141(3):805-814.

49. Powell RJ, Bhargava J, Basson MD, Sumpio BE. Coculture conditions alter endothelial modulation of TGF-beta 1 activation and smooth muscle growth morphology. Am J Physiol Heart Circ Physiol. 1998;274(2):H642-H649

50. Zhang JC, Ruan Q, Paucz L, Fabry A, Binder BR, Wojta J. Stimulation of tissue factor expression in human microvascular and macrovascular endothelial cells by cultured vascular smooth muscle cells in vitro. JVasc Res. 1999;36(2):126-132.

51. Isakson BE, Duling BR. Heterocellular contact at the myoendothelial junction influences gap junction organization. Circ Res. 2005;97(1):44-51.

52. van Kempen MJ, Jongsma HJ. Distribution of connexin37, connexin40 and connexin 43 in the aorta and coronary artery of several mammals. Histochem Cell Biol. 1999;112(6):479-486.

53. Discher DE, Janmey P, Wang Y-1. Tissue cells feel and respond to the stiffness of their substrate. Science. 2005;310(5751):1139-1143.

54. Heydarkhan-Hagvall S, Helenius G, Johansson BR, Li JY, Mattsson E, Risberg B. Co-culture of endothelial cells and smooth muscle cells affects gene expression of angiogenic factors. J Cell Biochem. 2003; 89(6):1250-1259.

55. Kurzen H, Manns S, Dandekar G, Schmidt T, Pratzel S, Kraling BM. Tightening of endothelial cell contacts: A physiologic response to cocultures with smooth-muscle-like 10T1/2 cells. J Invest Dermatol. 2002;119(1):143-153.

56. Redmond EM, Cahill PA, Sitzmann JV. Flow-mediated regulation of G-protein expression in cocultured vascular smooth muscle and endothelial cells. Arterioscler Thromb Vasc Biol. 1998;18(1):75-83.

57. Wallace CS, Strike SA, Truskey GA. Smooth muscle cell rigidity and extracellular matrix organization influence endothelial cell spreading and adhesion formation in coculture. Am J Physiol Cell Physiol. 2007;293(3):H1978-H1986.

58. Niklason LE, Gao J, Abbott WM, et al. Functional arteries grown in vitro. Science. 1999;284(5413):489-493.

59. Isenberg BC, Williams C, Tranquillo RT. Small-diameter artificial arteries engineered in vitro. Circ Res. 2006;98(1):25-35.

60. Hahn MS, McHale MK, Wang E, Schmedlen RH, West JL. Physiologic pulsatile flow bioreactor conditioning of poly(ethyleneglycol)-based tissue engineered vascular grafts. Ann Biomed Eng. 2007;35(2):190-200.

61. Beamish JA, Fu AY, Choi AJ, Haq NA, Kottke-Marchant K, Marchant RE. The influence of RGD-bearing hydrogels on the reexpression of contractile vascular smooth muscle cell phenotype. Biomaterials. 2009;30(25):4127-4135. 
62. Imberti B, Seliktar D, Nerem RM, Remuzzi A. The response of endothelial cells to fluid shear stress using a co-culture model of the arterial wall. Endothelium. 2002;9(1):11-23.

63. Isenberg BC, Williams C, Tranquillo RT. Endothelialization and flow conditioning of fibrin-based media-equivalents. Ann Biomed Eng. 2006;34(6):971-985.

64. Wallace CS, Truskey GA. Quiescent smooth muscle cells in directcontact co-culture with endothelial cells inhibit TNF-alpha mediated endothelial cell activation. Am J Physiol Cell Physiol. 2010;299(2): H338-H346.

65. Rainger GE, Nash GB. Cellular pathology of atherosclerosis: Smooth muscle cells prime cocultured endothelial cells for enhanced leukocyte adhesion. Circ Res. 2001;88(6):615-622.

66. Dittrich PS, Manz A. Lab-on-a-chip: Microfluidics in drug discovery. Nat Rev Drug Discov. 2006;5(3):210-218.

67. Pouton CW, Haynes JM. Pharmaceutical applciations of embryonic stem cells. Adv Drug Deliv Rev. 2005;57(13):1918-1934.

68. Ebert AD, Svendsen CN. Human stem cells and drug screening: Opportunities and challenges. Nat Rev Drug Discov. 2010;9(5):367-372.

69. Arts CH, Hedeman Joosten PP, Blankensteijn JD, et al. Contaminants from the transplant contribute to intimal hyperplasia associated with microvascular endothelial cell seeding. Eur J Vasc Endovasc Surg. 2002;23(1):29-38

70. Yoder MC, Mead LE, Prater D, et al. Redefining endothelial progenitor cells via clonal analysis and hematopoietic stem/progenitor cell principals. Blood. 2007;109(5):1801-1809.

71. Stroncek JD, Grant BS, Brown MA, Povsic TJ, Truskey GA, Reichert WM. Comparison of endothelial cell phenotypic markers of late-outgrowth endothelial progenitor cells isolated from patients with coronary artery disease and healthy volunteers. Tissue Eng Part A. 2009; 15(11):3473-3486.

72. Simper D, Stalboerger PG, Panetta CJ, Wang S, Caplice NM. Smooth muscle progenitor cells in human blood. Circulation. 2002; 106(10):1199-1204.

73. Melero-Martin JM, de Obaldia ME, Kang S-Y, et al. Engineering robust and functional vascular networks in vivo with human adult and cord blood-derived progenitor cells. Circ Res. 2008;103(2):194-202.
74. Sung JH, Kam C, Shuler ML. A microfluidic device for a pharmacokinetic-pharmacodynamic (PK-PD) model on a chip. Lab Chip.2010;10(4):446-455.

75. Fernandes TG, Diogo MM, Clark DS, Dordick JS, Cabral JMS. High-throughput cellular microarray platforms: Applications in drug discovery, toxicology and stem cell research. Trends Biotechnol. 2009;27(6):342-349.

76. Wu M-H, Huang S-B, Lee G-B. Microfluidic cell culture systems for drug research. Lab Chip. 2010;10(8):939-956.

77. Bayless KJ, Kwak H, Su S. Investigating endothelial invasion and sprouting behavior in three-dimensional collagen matrices. Nat Protoc. 2009;4(12):1888-1898.

78. Arnaoutova I, Kleinman HK. In vitro angiogenesis: Endothelial cell tube formation on gelled basement membrane extract. Nat Protoc. 2010;5(4):628-635

79. Evensen L, Micklem DR, Link W, Lorens JB. A novel imaging-based high-throughput screening approach to anti-angiogenic drug discovery. Cytometry A. 2010;77A(1):41-51.

80. Moraes C, Chen J, Sun Y, Simmons CA. Microfabricated arrays for high-throughput screening of cellular response to cyclic substrate deformation. Lab Chip. 2010;10(2):341-348.

81. Chung S, Sudo R, Vickerman V, Zervantonakis I, Kamm R. Microfluidic platforms for studies of angiogenesis, cell migration, and cell-cell interactions. Ann Biomed Eng. 2010;38(3):1164-1177.

82. Vickerman V, Blundo J, Chung S, Kamm R. Design, fabrication and implementation of a novel multi-parameter control microfluidic platform for three-dimensional cell culture and real-time imaging. $L a b$ Chip. 2008;8(9):1468-1477.

83. Truskey GA, Yuan F, Katz DF. Transport Phenomenon in Biological Systems. 2nd ed. Upper Saddle River, NJ: Pearson/Prentice Hall; 2009.

84. McKinney VZ, Rinker KD, Truskey GA. Spatial distribution of intracellular adhesion molecule-1 expression in human umbilical vein endothelial cells exposed to sudden expansion flow. J Biomech. 2006;39(5): 806-817.

85. Pang Z, Niklason LE, Truskey GA. Porcine endothelial cells co-cultured with smooth muscle cells became pro-coagulant in vitro. Tissue Eng Part A. 2010;36(6):1835-1844.
International Journal of High Throughput Screening

\section{Publish your work in this journal}

International Journal of High Throughput Screening is an international, peer-reviewed, open access journal publishing original research, reports, editorials, reviews and commentaries dedicated to all aspects of high throughput screening, especially related to drug discovery and associated areas of biology and chemistry. The manuscript management sys-

\section{Dovepress}

tem is completely online and includes a very quick and fair peer-review system. Visit http://www.dovepress.com/testimonials.php to read real quotes from published authors.

Submit your manuscript here: http://www.dovepress.com/international-journal-of-high-throughput-screening-journal 